\title{
Alterations in myostatin expression are associated with changes in cardiac left ventricular mass but not ejection fraction in the mouse
}

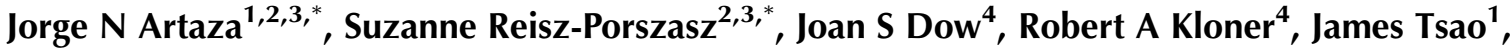 \\ Shalender Bhasin ${ }^{1,5}$ and Nestor F Gonzalez-Cadavid ${ }^{1,3}$ \\ ${ }^{1}$ Division of Endocrinology Metabolism and Molecular Medicine, ${ }^{2}$ Department of Biomedical Sciences and ${ }^{3}$ RCMI DNA Molecular Core, Charles R Drew \\ University of Medicine and Science, Los Angeles, California 90059, USA \\ ${ }^{4}$ The Heart Institute, Good Samaritan Hospital, Division of Cardiovascular Medicine of Keck School of Medicine at University of Southern California, LoS \\ Angeles, California 90017, USA \\ ${ }^{5}$ Section of Endocrinology, Diabetes, and Nutrition, Boston Medical Center, Boston, Massachusetts 02118, USA \\ (Requests for offprints should be addressed to N F Gonzalez-Cadavid at Division of Endocrinology, Metabolism, and Molecular Medicine, Charles R Drew \\ University of Medicine and Science, 1731 East 120th Street, Los Angeles, California 90059, USA; Email: ncadavid@ucla.edu) \\ *(J N Artaza and S Reisz-Porszasz are joint first authors) \\ (S Bhasin and N F Gonzalez-Cadavid contributed equally to this work)
}

\begin{abstract}
Myostatin (Mst) is a negative regulator of skeletal muscle in humans and animals. It is moderately expressed in the heart of sheep and cattle, increasing considerably after infarction. Genetic blockade of Mst expression increases cardiomyocyte growth. We determined whether Mst overexpression in the heart of transgenic mice reduces left ventricular size and function, and inhibits in vitro cardiomyocyte proliferation. Young transgenic mice overexpressing Mst in the heart (Mst transgenic mice (TG) under a muscle creatine kinase (MCK) promoter active in cardiac and skeletal muscle, and Mst knockout (Mst $(-/-))$ mice were used. Xiscan angiography revealed that the left ventricular ejection fraction did not differ between the Mst TG and the Mst $(-/-)$ mice, when compared with their respective wild-type strains, despite the decrease in whole heart and left ventricular size in Mst TG mice,
\end{abstract}

and their increase in Mst $(-/-)$ animals. The expected changes in cardiac Mst were measured by RT-PCR and western blot. Mst and its receptor (ActRIIb) were detected by RT-PCR in rat $\mathrm{H} 9 \mathrm{c} 2$ cardiomyocytes. Transfection of H9c2 with plasmids expressing Mst under muscle-specific creatine kinase promoter, or cytomegalovirus promoter, enhanced $\mathrm{p} 21$ and reduced $\mathrm{cdk} 2$ expression, when assessed by western blot. A decrease in cell number occurred by incubation with recombinant Mst (formazan assay), without affecting apoptosis or cardiomyocyte size. Anti-Mst antibody increased cardiomyocyte replication, whereas transfection with the Mst-expressing plasmids inhibited it. In conclusion, Mst does not affect cardiac systolic function in mice overexpressing or lacking the active protein, but it reduces cardiac mass and cardiomyocyte proliferation.

Journal of Endocrinology (2007) 194, 63-76

\section{Introduction}

Myostatin (Mst) is an endogenous negative regulator of skeletal muscle mass in rodents, cattle, other mammals, and fish (Lee 2004, Dominique \& Gerard 2006, Tsao et al. 2006, Tsuchida 2006). The Mst knockout mouse (Mst (-/ $)$ ), where Mst expression is genetically blocked (McPherron et al. 1997), and other transgenic mice where its processing into an active product is inhibited (Szabo et al. 1998, Zhu et al. 2000), display a considerable increase in skeletal muscle mass with both hypertrophy and hyperplasia. A child with an inactivating mutation of the Mst gene has also been shown to be hypermuscular (Schuelke et al. 2004). In contrast, ectopic overexpression of Mst by ex vivo transduced nonmuscle cells implanted into the mouse skeletal muscle (Zimmers et al. 2002), or by a transgenic mouse (Mst TG) that was engineered to overproduce Mst exclusively in the skeletal muscle (Reisz-Porszasz et al. 2003), leads to a predominant reduction of muscle mass. Although alterations in Mst expression are associated with reciprocal changes in skeletal muscle mass, they do not affect the specific force of the skeletal muscle (Caiozzo et al. 2005).

The biological activity of Mst is not limited to the skeletal muscle; the genetic inactivation of its expression is associated with leanness (McPherron et al. 1997, Szabo et al. 1998, Zhu et al. 2000, Yarasheski et al. 2002), whereas overexpression is associated with increased fat mass (Zimmers et al. 2002, Reisz-Porszasz et al. 2003). Furthermore, Mst also appears to have profibrotic effects in both the skeletal muscle and the corpora cavernosa of the penis by stimulating extracellular matrix deposition and myofibroblast formation (Wagner et al. 2002, Ferrini et al. 2004, McCroskery et al. 2005, Parsons et al . 
2006). This pleiotropic control of tissue composition may be related to the fact that Mst inhibits in vitro the myogenic differentiation of pluripotent cells and skeletal muscle-derived stem cells and stimulates their differentiation into fat cells and myofibroblasts (Ferrini et al. 2004, Artaza et al. 2005, 2006).

Although Mst was initially postulated to be expressed exclusively in the skeletal muscle and to a much lower extent in fat tissue (McPherron \& Lee 1997, McPherron et al. 1997, Gonzalez-Cadavid et al. 1998), low levels of Mst have been detected in the myocardial tissues of sheep, fish, and cattle (Sharma et al. 1999, Ostbye et al. 2001, Gregory et al. 2004). Mst protein has been localized in cardiomyocytes in the ovine heart, more specifically in Purkinje fibers, and Mst expression is upregulated after experimentally induced myocardial infarction (Sharma et al. 1999). Myocardial Mst mRNA and protein expression were also upregulated in the rat model of volume overload heart failure (Shyu et al. 2006). The Mst precursor protein was also detected in the heart of fish, among other organs, by western blot (Ostbye et al. 2001, Gregory et al. 2004).

Overexpression of Mst in the skeletal muscle and heart of the Mst $(+/+)$ male mouse was associated with lower heart weight (Reisz-Porszasz et al. 2003), despite the fact that a reduction in heart size had also been observed in animals not expressing active Mst, the Belgian blue bull (Sharma et al. 1999), and in an inbred line of mice where the Compact Mst mutation was introduced (Bunger et al. 2004). In line with the latter observations, in transgenic mice with cardiac-specific expression of activated Akt, which reduces cardiomyocyte death and induces cardiac hypertrophy, Mst expression in the heart was considerably induced (Cook et al. 2002).

However, the apparent paradox of Mst expression being associated with cardiac hypertrophy appears to be resolved by the demonstration that cyclic mechanical stretch, which causes cardiomyocyte growth in vitro, leads to Mst overexpression as a compensatory mechanism to insulin-like growth factor-I secretion induced by stretch (Shyu et al. 2005). This confirms the role of Mst as a chalone to control heart growth (Gaussin \& Depre 2005), which has been further demonstrated in cardiomyocytes from the transgenic mouse with Akt activation, where Mst abrogates their in vitro growth caused by phenylephrine, through inhibition of p38 and Akt. Conversely, in vivo infusion of Mst $(-/-)$ hearts with phenylephrine leads to considerable increases in $\mathrm{p} 38$ phosphorylation and Akt kinase activity (Morissette et al. 2006).

Thus, the effects of Mst on myocardial mass and function remain poorly understood and were the subject of this investigation. Accordingly, we determined the effects of alterations in Mst expression on myocardial mass and function in Mst transgenic mice that overexpress Mst and Mst knockout mice with diminished Mst expression. To obviate confounding factors due to the effect of aging and sexual maturation on myocardial size and function (Hacker et al. 2006, Rozenberg et al. 2006), we studied myocardial function in sexually mature, 7-week-old mice. We also considered the possibility that in transgenic mice that overexpress Mst, the alterations in myocardial size and function could result from endocrine effects of Mst secreted by the skeletal muscle rather than the direct effect of Mst expressed in the myocardial tissue. Therefore, we evaluated the myocardial mass and function in transgenic mice in which Mst expression was restricted to the heart and skeletal muscle by using a MCK promoter. Since Mst inhibits proliferation of skeletal muscle precursor cells, we determined the effects of recombinant Mst protein on the proliferation of $\mathrm{H} 9 \mathrm{c} 2$ cardiomyocytes in vitro and whether it affected cell size and apoptosis.

\section{Material and Methods}

\section{Animals}

We generated two sets of transgenic mice on a C57BL/6J background that overexpress Mst protein under either the muscle-specific creatine kinase (MCK) promoter (active in both skeletal muscle and heart), MCK-Mst TG, or the mutated MCK-3E promoter (active only in skeletal muscle), MCK-3EMst TG (Shield et al. 1996, Reisz-Porszasz et al. 2003). The strategy for the generation of these transgenic mice and their skeletal muscle phenotype has been described previously (Reisz-Porszasz et al. 2003). The enhanced green fluorescent protein (pEGFP) reporter mice included the C57BL/6J/MCKpEGFP and the C57BL/6J/MCK-3E-pEGFP transgenic mice that express EGFP in BL/6J mice under either the MCK or MCK-3E promoter (Reisz-Porszasz et al. 2003, Caiozzo et al. 2005). Seven-week-old male mice were used in all cases $(n=$ 6-11 animals/group).

Mst knockouts, Mst $(-/-)$, mice, provided kindly by Dr $\mathrm{S} \mathrm{J}$ Lee, were bred in our vivarium (BalbC/Mst $(-/-)$; McPherron et al. 1997). As reported previously by Dr Lee's group, these Mst null mice show greater muscularity and lower fat mass than age-matched wild-type (WT) controls.

\section{Evaluation of heart function}

Mice were anesthetized with an i.p. injection of ketamine and xylazine $(200$ and $10 \mathrm{mg} / \mathrm{kg}$ respectively). The neck was shaved to expose left jugular vein and a catheter was inserted for injection of contrast media (Optiray-320) and potassium chloride (KCl). Angiograms (Muller-Ehmsen et al. 2002) were performed using a XiScan (Xi Tec Inc., East Windsor, CT, USA) portable c-arm X-ray system, $30 \mathrm{~min}$ after anesthesia. With the animal positioned on its back or right side, and the XiScan running, media $(0.2 \mathrm{ml}$ per view) was rapidly injected, to capture images of the heart in the anterior-posterior and lateral views of the left ventricle $(\mathrm{LV})$. Images were captured on half-inch super-VHS videotape at 30 frames per second. Video images were analyzed off-line. Three consecutive beats from each image (if available) was analyzed. For each beat, the LV cavity was traced in both diastole and systole. Measurements included circumference, area, length, and volume. Ejection fraction (EF) was calculated as: (end diastolic volume-end systolic volume)/ end diastolic volume $\times 100$. These measurements were then averaged for each view. Mice were euthanized with an injection of $\mathrm{KCl}$ once the angiograms had been performed. 


\section{Cell culture}

H9c2 rat embryonic cardiomyocytes (Gregory et al. 2004) were obtained from American Type Culture Collection (ATCC; Rockville, MD, USA), and were maintained in Dulbecco's modified Eagle's medium (DMEM, Cambrex Bio Science Walkersville Inc., Walkersville, MD, USA), supplemented with $10 \%$ fetal bovine serum (Gibco BRL), $4 \mathrm{mM}$ glutamine, $4.5 \mathrm{~g} / 1$ glucose, $100 \mathrm{IU} / \mathrm{ml}$ penicillin, and $100 \mu \mathrm{g} / \mathrm{ml}$ streptomycin (Life Technologies) and incubated at $37^{\circ} \mathrm{C}$ in $5 \% \mathrm{CO}_{2}$, at $30-50 \%$ confluence. These cells are defined as embryonic by ATCC because they were obtained from rat embryos, and are acknowledged as such in the literature. The cells were transfected with Mst cDNA constructs expressing the full length 375 aa mouse protein, in the presence of lipofectamine (Invitrogen) using $2 \mu \mathrm{g}$ total plasmid DNA at a 1:4 ratio of either $\mathrm{pCMV/EGFP} \mathrm{to} \mathrm{pCMV/Mst}$ or $\mathrm{pMCK} / \mathrm{EGFP}$ to $\mathrm{pMCK} /$ Mst constructs (Reisz-Porszasz et al. 2003, Artaza et al. 2005, Magee et al. 2006). Transfection efficiency was followed by green fluorescence expression. Cells were harvested after 3 days of transfection and total RNA and protein were isolated. Alternatively, cells were replated and growth curves were performed by the cell proliferation assay.

For treatments with recombinant Mst protein, cells were incubated in $12-$ well plates with $4-8 \mu \mathrm{g} / \mathrm{ml}$ of the $16 \mathrm{kDa}$ recombinant human Mst protein corresponding to the 110 aa (carboxy terminus; Artaza et al. 2005, 2006) or 3·3-33 $\mu \mathrm{g} / \mathrm{ml}$ of our custom-made polyclonal anti-Mst antibody (Gonzalez-Cadavid et al. 1998, Artaza et al. 2005, 2006) in DMEM-10\% serum for 2 days. The recombinant protein was tested for its biological activity in $\mathrm{C}_{2} \mathrm{C}_{12}$ cells (Taylor et al. 2001, Artaza, et al. 2002). The recombinant Mst protein was obtained from BioVendor Laboratory Medicine Inc., Czech Republic.

\section{Cell proliferation assay}

It was determined in 96-well plates by the Formazan dye assay (Promega Corp.; Taylor et al. 2001). The cells were grown at an initial density of 4000 cells/well; then after 1 day, they were treated for $72 \mathrm{~h}$ with recombinant Mst protein in varying concentrations, with Mst polyclonal antibody in a $1 / 100$ dilution, with $\mathrm{IgG}$ isotype and transforming growth factor (TGF) $\beta 1$ recombinant protein at $10 \mathrm{ng} / \mathrm{ml}$ concentration as positive control. After 3 days of incubation, $100 \mu$ of Formazan substrate buffer was added to the cultures for $3 \mathrm{~h}$ at $37^{\circ} \mathrm{C}$ in $5 \%$ $\mathrm{CO}_{2}$, and the absorbance at $492 \mathrm{~nm}$ was read by an ELISA plate reader. For cell counting, the cells were removed by trypsinization and the number of viable cells was counted in a hemocytometer with the use of Trypan blue staining.

\section{Immunocytochemical analyses}

For immunocytochemical characterization, cells were seeded at $60-70 \%$ confluence onto 8-well chamber slides, treated with recombinant Mst protein and fixed in 2\% paraformaldehyde at different time points; quenched with $\mathrm{H}_{2} \mathrm{O}_{2}$, blocked with normal goat or horse serum and incubated with specific antibodies (Schreier et al. 1990, Artaza et al. 2002, 2005, Magee et al. 2006). Mst polyclonal antibody $1 / 500$ dilution; cardiac troponin T (Santa Cruz Biotechnology Inc., Santa Cruz, CA, USA) dilution 1/500; myosin heavy chain (MHC) type I dilution 1/40 and MHC type II (1/40; Novocastra Laboratories Ltd, Newcastle, UK). Detection was based on a secondary biotinylated antibody $(1 / 200)$, followed by the addition of the streptavidin-horseradish peroxidase ABC complex (1/100); Vectastain Elite ABC System, (Vector Laboratories, Burlingame, CA, USA) and 3,3'-diaminobenzidine (Sigma). In the case of Mst monoclonal antibody generated by our group against the Mst-113 aa (mature fraction), we used the mouse on mouse (MOM; Vector Laboratories) immunodetection system, which provides a significant reduction of background staining on tissues or cells from mouse origin. The cells were counterstained with Meyer's hematoxylin. In negative controls, we either omitted the first antibody or used a rabbit nonspecific IgG.

Apoptosis. The apoptotic index was determined by the TdT-mediated dUTP nick end labeling (TUNEL) method, based on the ability of terminal TdT to catalyze addition of digoxenin-dUTP and dATP to $3^{\prime}-\mathrm{OH}$ ends of cleaved DNA. The cells were placed on removable 8 -well chamber slides and incubated with or without Mst for 1-3 days and then fixed in $2 \% p$-formaldehyde. The slides were treated with proteinase $\mathrm{K}$ and $\mathrm{H}_{2} \mathrm{O}_{2}$ followed by the addition of primary and secondary antisera. The chambers were stained with $3,3^{\prime}-$ diaminobenzidine and sections were counter-stained with hematoxylin. Negative controls in the immunohistochemical detections were done by replacing the first antibody with IgG isotype. The negative control for TUNEL was by substituting buffer for the TdT enzyme (Taylor et al. 2001).

\section{Quantitative image analysis}

Quantitative image analysis was performed by computerized densitometry using the ImagePro 5.1 program (Media Cybernetics, Silver Spring, MD, USA), coupled to an Olympus BHS microscope equipped with an Olympus digital camera (Artaza et al. 2005).

For TUNEL determinations, the number of positive cells at $400 \times$ was counted and results were expressed as a percentage of positive cells/total cells. Negative controls without primary or secondary antibodies were performed to correct for antibody specificity and background intensity. In all cases, 20 fields at $400 \times$ magnification were selected at random and the apoptotic index of each field was calculated as the percent of TUNEL-positive cells. For cell size determination, cells were stained with Troponin A as above and the area covered by the stain was measured by quantitative image analysis and the average was expressed in $\mu \mathrm{m}^{2}$.

\section{Western blot analysis}

Cell lysates (50-100 $\mu \mathrm{g}$ of protein) were subjected to western blot analyses by $7 \cdot 5$ or $12 \%$ gel electrophoresis 
(Gonzalez-Cadavid et al. 1998, Taylor et al. 2001, Artaza et al. 2002, 2005, Reisz-Porszasz et al. 2003, Magee et al. 2006) using our monoclonal or polyclonal antibodies for Mst (1/500), as indicated, and polyclonal antibodies for p21 (cyclin kinase inhibitor; $1 / 500)$, cdk2 cyclin-dependent kinase 2 (1/500), and monoclonal antibody for glyceraldehyde-3-phosphatedehydrogenase (GAPDH; 1:10 000; all from Chemicon International, Temecula, CA, USA). The washed membranes were incubated with 1:1000 dilution, or 1/3000 for Mst, of secondary antibody linked to horseradish peroxidase. Immunoreactive bands were visualized by using the emission of chemiluminescence (ECL) plus western blotting chemiluminescence detection system (Amersham; Artaza et al. 2005).

\section{$R T-P C R$}

Two micrograms of total RNA, extracted from heart tissue or cardiomyocytes using the Trizol-Reagent (Invitrogen), was reverse transcribed, and cDNA was amplified for 35 cycles by PCR at $94^{\circ} \mathrm{C}$ for $30 \mathrm{~s}$, primer annealing at $58^{\circ} \mathrm{C}$ for $30 \mathrm{~s}$, and extension at $72{ }^{\circ} \mathrm{C}$ for $1 \mathrm{~min}$ (Gonzalez-Cadavid et al. 1998, Taylor et al. 2001, Artaza et al. 2002, 2005, Reisz-Porszasz et al. 2003, Magee et al. 2006). PCR products were analyzed in 1.5\% agarose gels. The sequences of the Mst forward/ reverse PCR primers are as follows: (i) P1 primers for WT Mst: forward: 5'-GACAAAACACGAGGTACTC, reverse: 5'-TGGATTCAGGCTGTTTG AGC (531 bp); (ii) P2 primer for transgene Mst: forward: $5^{\prime}$-GTCTCCCATTAATATGCTAT, reverse: 5'-GGGAGGTGTGGGAGGTTTT (175 bp); (iii) primers for GAPDH (152 bp): forward primer: 5'-ATCACTGCCACCCAGAAGACT, reverse primer: 5'-CATGCCAGTGAGCTTCC CGTT; and (iv) primers for Act RIIb: forward 5'-GCCTCTCTCTCATCGTCCTG (545-564 bp), reverse 5'-GACTGCTTGTCCTGAAGTGG (779-760 bp). The PCR fragment is $235 \mathrm{bp}$ in length.

\section{Statistical analysis}

All data are presented as mean \pm s.E.M., and between-group differences were analyzed by using ANOVA. If overall ANOVA revealed significant differences, then pairwise comparisons between groups were performed using Newman-Keuls multiple comparison test. All comparisons were two-tailed, and $P$ values $<0.05$ were considered statistically significant. The in vitro experiments were repeated twice to thrice, and data from representative experiments are shown.

\section{Results}

Mst is an endogenous negative regulator of heart and LV size

As shown in Fig. 1A, Mst TG mice in which the MCK promoter directed Mst expression have consistently slightly lower body weights over the first 7 weeks of postnatal development, in comparison to the WT mice of the same strain. Body weights in Mst TG mice tend to become more similar to the WT animals between 7 and 8 weeks of age (Reisz-Porszasz et al. 2003). The MCK promoter drives the expression of Mst not only in the skeletal muscle, but also in the heart. Tissue sections from the heart of transgenic mice that express the enhanced green fluorescent protein driven by the mouse MCK promoter demonstrate intense green fluorescence in the myocardial tissue, consistent with the expression of the transgene in the myocardium (B, left). In contrast, similar tissue sections from transgenic mice in which EGFP expression was driven by the mutated MCK promoter (MCK-3E; Reisz-Porszasz et al. 2003) showed EGFP expression in the skeletal muscle, but not in the myocardium, confirming the ability of MCK-3E, the mutated MCK promoter, to restrict gene expression to the skeletal muscle (B right).

The mean heart weights in male transgenic mice, in which Mst transgene was expressed in both the skeletal and myocardial muscles, were significantly lower (mean difference in heart weights $11 \%$ ) than age-matched WT controls (Fig. 1C left). Significantly, the mean heart weights in transgenic mice carrying the MCK-3E skeletal muscle-specific promoter that restricted the expression of the $M s t$ transgene to the skeletal muscle did not differ significantly from those of WT controls (data not shown). This suggests that Mst effects on heart weight are not endocrine due to circulating Mst secreted from the skeletal muscle, but rather autocrine or paracrine, as these effects were observed only when Mst was also expressed in the myocardium itself and not when its expression was confined to the skeletal muscle. The heart weights of the Mst $(-/-)$ mice on a Balb c background were significantly higher than that of their respective age-matched WT controls (mean difference in heart weights $24 \%$ ).

The reduction in the heart weight observed in the Mst TG mouse was mostly due to the lower left ventricular mass; even after correction by body weight, the left ventricular mass in male transgenic mice was $21 \%$ lower than in the corresponding WT controls (C, right).

To confirm that the differences in cardiac size correlated with Mst expression in the heart, RT-PCR reactions were performed on RNAs isolated from this tissue as well as from the Mst TG and Mst $(-/-)$ animals. Figure 2A shows the two set of primers, $\mathrm{P} 1$ and $\mathrm{P} 2$, used for these reactions that respectively encompass the Mst coding region bridging two exons (to eliminate any potential DNA interference) or the $3^{\prime}$ end and part of the SV40 polyA signal that is transcribed from the Mst cDNA construct used to generate the Mst TG mouse. As expected, the $\mathrm{P} 1$ primers did not amplify any DNA band in the RNA from four Mst $(-/-)$ hearts, although the $531 \mathrm{bp}$ band was clearly visible in the positive control from skeletal muscle (B). The intensity of this band was moderate but variable in the RNA from the hearts of the WT mice and more consistent in the Mst TG mice, thus indicating that Mst mRNA is endogenously expressed in the heart of WT animals, and overexpressed in the transgenic mice. The RNA reverse transcribed and amplified with the $\mathrm{P} 2$ set of primers showed an intense $175 \mathrm{bp}$ band in the Mst TG hearts, and none in the Mst 
A

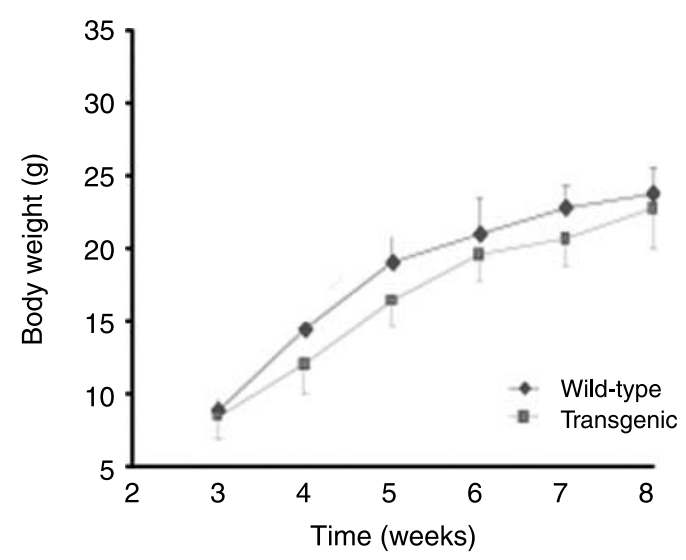

B

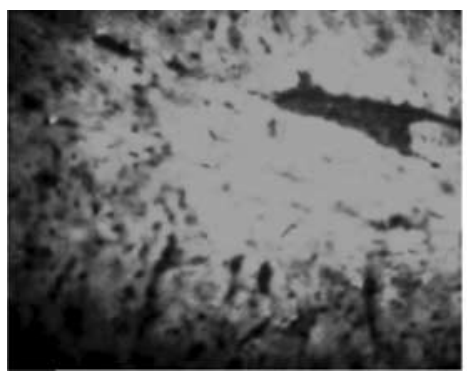

MCK-EGFP

C

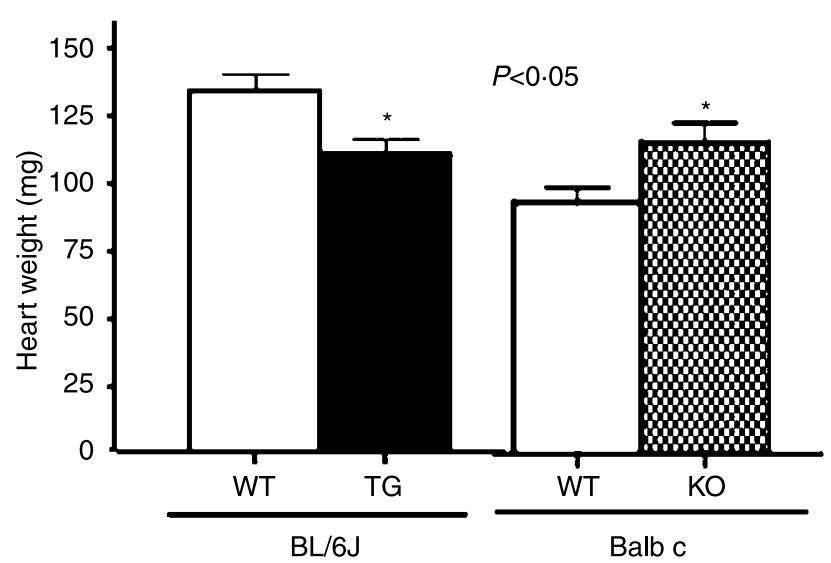

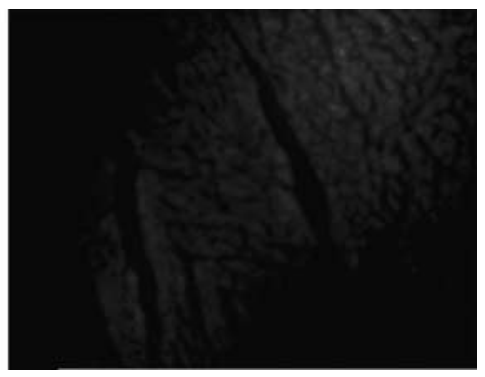

MCK-3E-EGFP

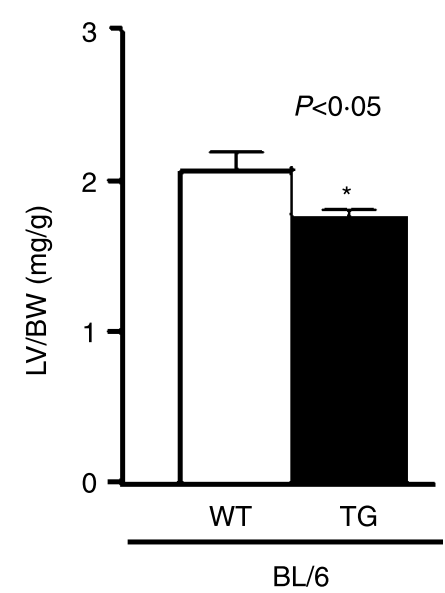

Figure 1 Genetic blockade or overexpression of myostatin in the Mst (-/-) and Mst TG mice affects heart and left ventricle size. (A) Mst TG mice growth curves. (B) Heart tissue from 7-week-old MCK/EGFP and MCK-3E transgenic mice was excised, fixed, cut in $6 \mu \mathrm{m}$ sections, and examined under the fluorescent regular microscope. (C) Heart weights (left) and left ventricle weights corrected by body weights in mice. WT, wildtype (Mst $(+/+)$ ) mice; TG, transgenic overexpressing myostatin, Mst TG mice; KO, myostatin knockout (Mst $(-/-))$ mice; MCK and MCK-3E denote the respective promoters in the Mst TG mice. ${ }^{*} P<0 \cdot 05$.

$(-/-)$, as expected $(\mathrm{C})$, thus confirming the identity and expression of the exogenously transcribed Mst RNA.

Parallel to the RNA results, Mst protein was barely detectable in the hearts of WT mice on western blots using an anti-Mst monoclonal antibody that in the skeletal muscle detects a $50-52 \mathrm{kDa}$ band that is assumed to be the monomer of the full length unprocessed precursor, and a $30-32 \mathrm{kDa}$ band assumed to be a glycosylated dimer of the carboxy terminus portion of the full length translational product (Gonzalez-Cadavid et al. 1998, Artaza et al. 2005; Fig. 3A, left). The $52 \mathrm{kDa}$ band for the precursor was seen in the homogenates from the six Mst TG transgenic hearts, in some of them rather intense, and this band was absent, as expected, in the Mst $(-/-)$ mice. The $32 \mathrm{kDa}$ processed band was not 


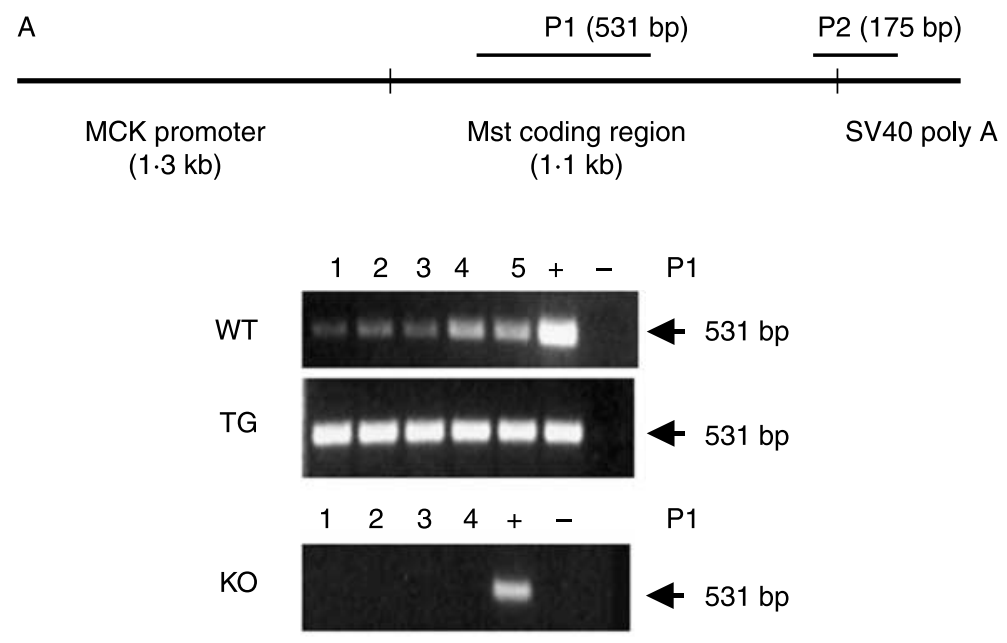

B

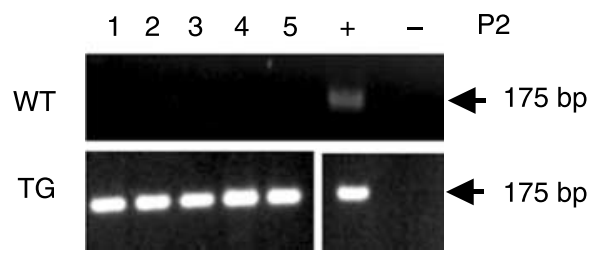

Figure 2 Relative expression of myostatin RNA in the heart of the Mst TG and wildtype mice, determined by RT-PCR. (A) Schematic of the P1 and P2 set of primers to detect both endogenous and recombinant myostatin (P1), or recombinant myostatin only (P2). (B) RNA was isolated form total cardiac tissue from Bl6J background mice and subjected to RT-PCR with the P1 set of primers, identifying amplified DNA bands by ethidium bromide staining after agarose gel electrophoresis. (C) Similar reactions were carried out with the P2 set of primers. For other symbols see Fig. 1.

evident on this gel. The densitometric comparison showed a twofold increase in the Mst TG when compared with WT (A, right). However, when double the protein was loaded in another run and western blotted and the X-ray was over exposed (B), a clear $32 \mathrm{kDa}$ band was detected in the TG heart, which was very faint but visible in the WT, where the $52 \mathrm{kDa}$ band was also clear. Both the 52 and $32 \mathrm{kDa}$ bands were absent in the Mst $(-/-)$ heart tissue, as expected.

\section{Left ventricular EFs are normal in Mst transgenic mice}

In spite of the differences in heart weight, and specifically in left ventricular weight, in parallel with the differences in cardiac Mst expression, the Mst transgenic mice had an EF in the anterior/posterior view (AP) that was not different from the one in their respective WT controls in the BL/6 background (Fig. 4A, left). The same situation occurred in the Mst $(-/-)$ mice when compared with their respective WT controls in the Balbc background (A, right). The lateral view confirmed these observations (B left and right).
The end systolic volumes in the AP view reflected the differences in heart sizes (AP: Mst TG: 0.015 $\pm 0 \cdot 001$ versus WT: $0 \cdot 018 \pm 0 \cdot 002$, and Mst $(-/-): 0 \cdot 021 \pm 0 \cdot 004$ versus WT: $0 \cdot 012 \pm 0 \cdot 003)$, and the same occurred with the end diastolic volumes (AP: Mst TG: 0.038 $\pm 0 \cdot 002$ versus WT: $0 \cdot 044 \pm 0 \cdot 005 ;$ and Mst $(-/-): 0 \cdot 050 \pm 0 \cdot 003)$. The lateral view showed the same trend but with less marked differences (not shown). In other words, irrespective of the significant changes in heart size, and particularly in LV size, due to the opposite degrees of Mst expression, the EF did not differ significantly between the Mst transgenic and Mst knockout and their corresponding WT controls.

\section{Mst inhibits replication of cardiomyocytes without affecting apoptosis or cell size}

Since Mst effects on heart size and function in transgenic and knockout mice are probably cumulative over the whole gestational and early postnatal period until the 7 weeks of age we chose for measurements, it is unlikely that the changes in gene expression that may affect cardiac size would be so 
A

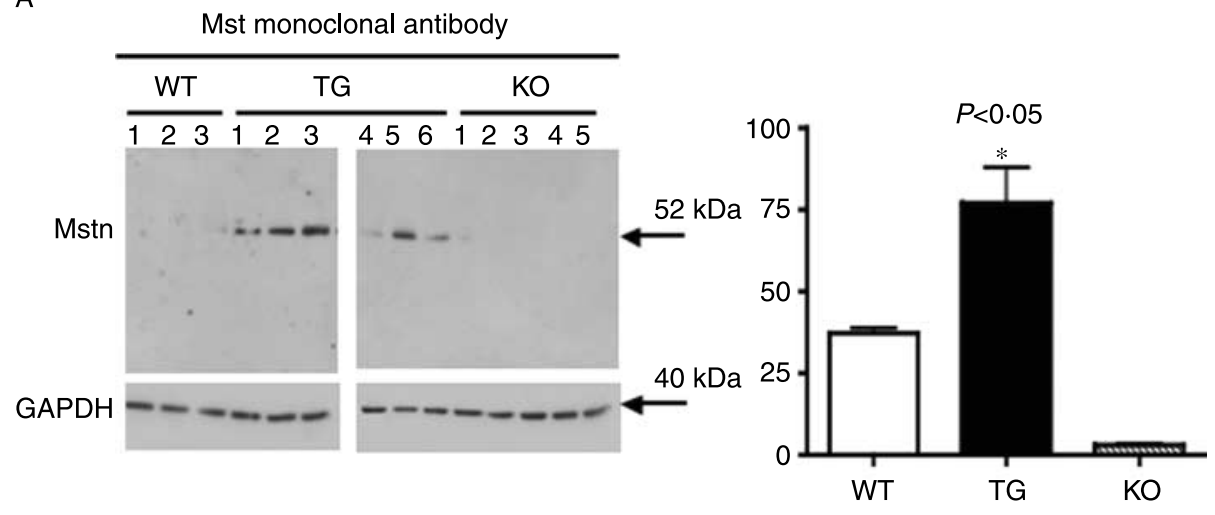

B

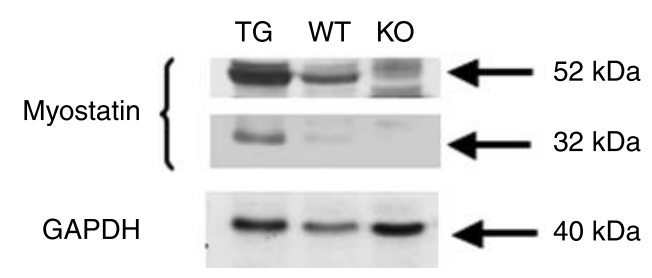

Figure 3 Relative expression of myostatin protein in the heart of the Mst $(+/+)$ and wild-type mice, determined by western blot. (A) Left: total protein was obtained from mouse hearts different from those on Fig. 2, and subjected to western blot analysis (20 $\mu \mathrm{g}$ protein) for myostatin, using a monoclonal antibody and GAPDH as housekeeping reference protein. Right: densitometric analysis. (B) In a separate gel, the loading was $40 \mu \mathrm{g}$ and the X-ray was overexposed to intensify bands, so that the expression of myostatin in the wild-type heart was more evident.

significant, or even persist, as to be detected unequivocally at the time of killing. Therefore, we decided to study these possible effects of Mst in vitro in an accepted cardiomyocyte cell line of embryonic origin, the $\mathrm{H} 9 \mathrm{c} 2$ cells. First, we aimed to detect Mst protein expression in these cells by immunocytochemistry with our polyclonal antibody. Figure 5A shows that it is localized predominantly in the nuclei, as previously seen (Artaza et al. 2002), thus confirming the previous observation in sheep (Sharma et al. 1999) that the modest expression of Mst seen in the heart of the WT mice occurs in the cardiomyocytes themselves. The immunocytochemical determination of the cardiomyocyte marker, cardiac troponin I (B) along with the lack of expression of MHC type I (C) and II (D) confirmed the purity of the H9c2 cell culture. Further confirmation of the endogenous production of Mst was obtained by RT-PCR with primers specific for Mst that shows the $531 \mathrm{bp}$ DNA band reverse transcribed and amplified from the $\mathrm{H} 9 \mathrm{c} 2$ RNA (E). This set of primers overlap two exons in the Mst DNA coding region, thus excluding contamination with genomic DNA. This band was also seen, as expected, in the reactions from C2C12 myotubes (Taylor et al. 2001) and C3H 10T (1/2) cells differentiated with $5^{\prime}$-azacytidine (Artaza et al. 2005).

In order to decide whether Mst in the heart, presumably translated from RNA in the cardiomyocytes, would act exclusively in an autocrine fashion or may also be secreted and interact with membrane bound receptors, we investigated whether RNA for the Mst receptor, the ActRIIB, is also expressed in cardiomyocytes, in this case, the $\mathrm{H} 9 \mathrm{c} 2$ cells. Figure $5 \mathrm{~F}$ shows that this is the case since the corresponding $235 \mathrm{bp}$ DNA band was detected after RT-PCR of the H9c2 cells RNA, as well as in the reaction from the $\mathrm{C} 2 \mathrm{C} 12$ and C3H 10T(1/2) RNAs.

To test the hypothesis that Mst decreases cardiac muscle mass by inhibiting cardiomyocyte proliferation, H9c2 cells were transfected in the presence of lipofectamine with two types of constructs encoding the full length Mst cDNA under either the strong, tissue unspecific, CMV promoter, or the weak, skeletal muscle/heart-specific, MCK promoter.

A parallel test with similar constructs expressing the reporter gene EGFP in lieu of Mst showed that both promoters were activated in the cells as expected, and that the level of transfection were reasonable for both constructs (Fig. 6A). Western blot analysis for several proteins present in the cell extracts from non-transfected cultures and the cells transfected with the Mst plasmids is presented in Fig. 6B. The polyclonal antibody against Mst detected a faint expression of the $32 \mathrm{kDa}$ band for the glycosylated dimer, thus confirming that the Mst mRNA in the H9c2 cells seen in Fig. 5 is indeed translated into protein. Transfection with the Mst cDNA constructs resulted in a much more intense $32 \mathrm{kDa}$ band indicating Mst processing by the cardiomyocytes. The 

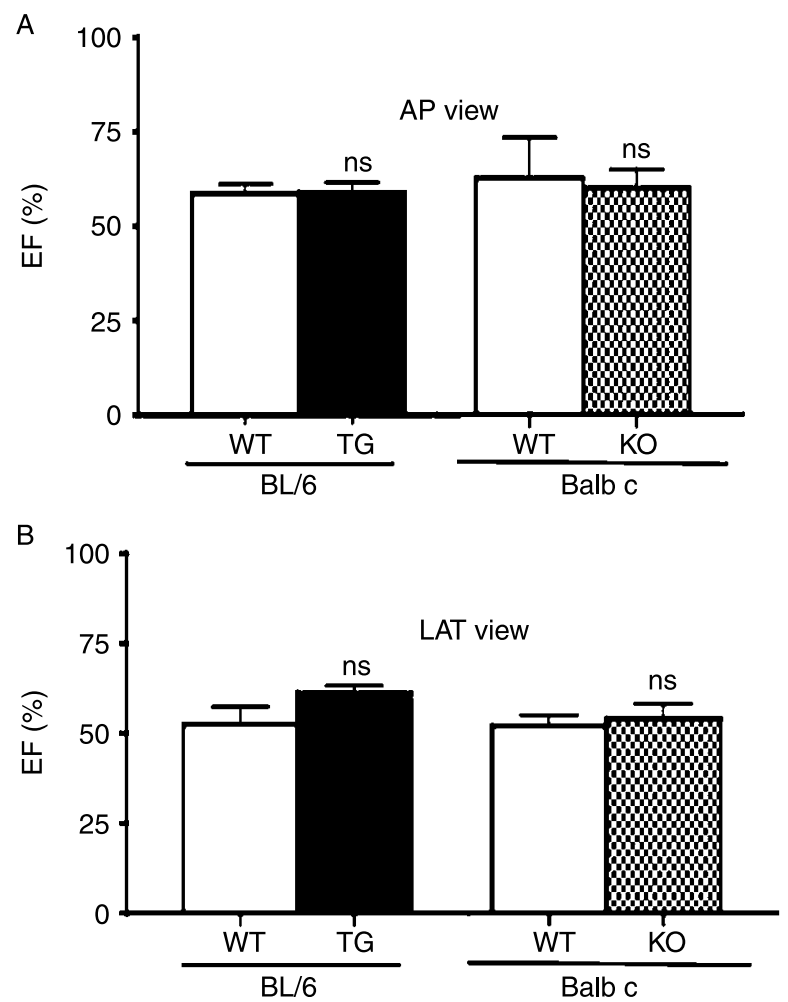

Figure 4 Genetic blockade or overexpression of myostatin in the Mst $(-/-)$ and Mst TG mice affects left ventricle size in the male animal, but not cardiac function. (A) Ejection fraction in mice under the anterior/posterior position determined by angiograms. Ejection fraction: (EDV-ESV)/EDV. (B) Ejection fraction under the lateral view. For other symbols see Fig. 1.

housekeeping gene, GAPDH, was virtually similar in the three extracts.

The expression of the cell cycle inhibitor p21 was virtually negligible in the untransfected $\mathrm{H} 9 \mathrm{c} 2$ cells, and the reverse occurred with the cyclin $\mathrm{Cdk} 2$, as expected from proliferating cells (Fig. 6B). Mst overexpression by both Mst cDNA constructs led to much higher p21 levels and lower cdk2, thus suggesting that Mst induces the exit from the cell cycle that would reduce cell proliferation in vitro and tissue growth in vivo.

In order to determine whether Mst does indeed inhibit cardiomyocyte replication, $\mathrm{H} 9 \mathrm{c} 2$ cells were incubated with increasing concentrations of the recombinant Mst protein corresponding to the 110 aa (carboxy terminus; Mst 110), the processed active Mst fragment, from 0 to $8 \mu \mathrm{g} / \mathrm{ml}$, starting at a low confluence $(20 \%)$ for 4 days, and proliferation was estimated by a formazan assay (Fig. 7A). Mst at 4 and $6 \mu \mathrm{g} / \mathrm{ml}$ induced a statistically significant reduction in cell number that increased only moderately with $8 \mu \mathrm{g} / \mathrm{ml}$. The paracrine inhibitory activity of Mst was low in comparison to the one of TGF $\beta 1$ at $10 \mathrm{ng} / \mathrm{ml}$. In contrast, incubation with the polyclonal rabbit IgG antibody against Mst $(100 \mu \mathrm{g} / \mathrm{ml})$ produced statistically significant stimulation of $\mathrm{H} 9 \mathrm{c} 2$ cell proliferation, whereas the nonimmune $\operatorname{IgG}$ at the same concentration did not have any effect.
When $\mathrm{H} 9 \mathrm{c} 2$ cells were transfected with the two plasmid constructs expressing Mst under the CMV or MCK promoter, there was statistically significant reduction in cell proliferation measured as in the experiment with recombinant Mst, when compared with the controls either without transfection, incubated with lipofectamine only, or transfected with an empty pcDNA 3.0 CVM plasmid (Fig. 7B). There was no significant difference in cell proliferation among the control incubations.

To confirm that Mst may reduce cardiac size by downregulating the number of cardiomyocytes mainly via the inhibition of cell replication and not through the induction of cell death, we repeated the incubations of $\mathrm{H} 9 \mathrm{c} 2$ cells with recombinant Mst protein at $4 \mu \mathrm{g} / \mathrm{ml}$ for 3 days. Figure $8 \mathrm{~A}$ and $\mathrm{C}$ left, shows with the TUNEL reaction followed by quantitative image analysis that there was no significant effect of Mst on the cardiomyocytes apoptotic index. The alternative possibility, namely that Mst would reduce cardiomyocyte size was excluded in vitro, since we did not find any significant difference in the presence or absence of Mst (B and C right).

\section{Discussion}

To our knowledge, this is the first demonstration that Mst overexpression in the heart of the Mst TG mouse is associated with decreased cardiac left ventricular mass, without a significant change in the fractional ejection volume. Similarly, decreased Mst expression in the Mst $(-/-)$ mice was associated with increased cardiac mass without a significant functional change. By focusing on the in vitro effects of Mst on a widely used cardiomyocyte cell culture, in order to amplify molecular and cellular changes that may not be readily apparent in vivo due to the uncertainty on when Mst acts during gestational and postnatal development period in the mouse, we aimed to detect a potential mechanism of action that would explain the in vivo effects of Mst on cardiac size. We found that Mst inhibits proliferation of $\mathrm{H} 9 \mathrm{c} 2$ cardiomyocytes in vitro, an effect that is blocked by anti-Mst antibody. Transfection of H9c2 cardiomyocytes with a Mst expression cDNA construct also is associated with decreased cell replication. Additionally, Mst upregulates the expression of $\mathrm{p} 21$, an inhibitor of cdk2 and downregulates cdk2 in cardiomyocytes, but does not affect apoptosis or cardiomyocyte size. Collectively, these data suggest that Mst reduces cardiac size during development mainly by inducing replicating cardiomyocytes to exit the cell cycle. It is unlikely that this would occur once cardiac growth is arrested in the animal along its lifespan or under conditions of cardiac hypertrophy in the mature heart.

The selective effects of Mst on cardiomyocyte mass but not on EF are analogous to those found in the skeletal muscle, where Mst-induced changes in muscle mass are not associated with changes in specific tension generation (Caiozzo et al. 2005). In other words, the contractile units in both tissues retain the same functional efficacy. The XiScan small imaging amplifier used in this study has previously been applied to 
$400 \mathrm{X}$

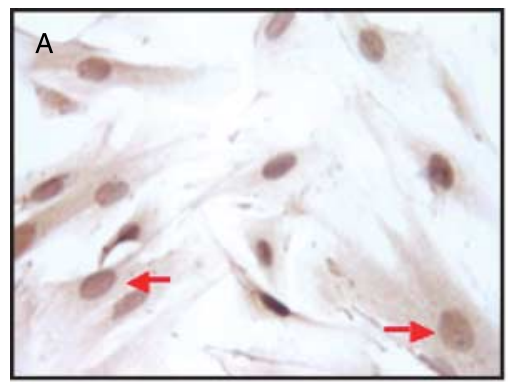

Myostatin

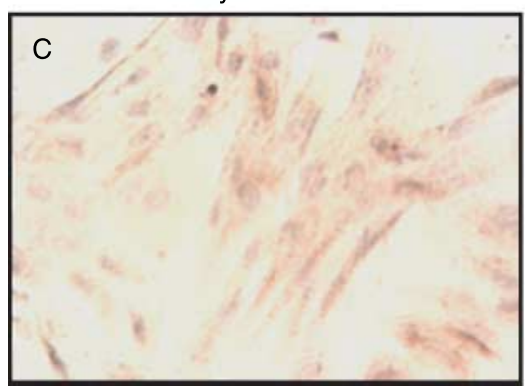

MHC type I

E

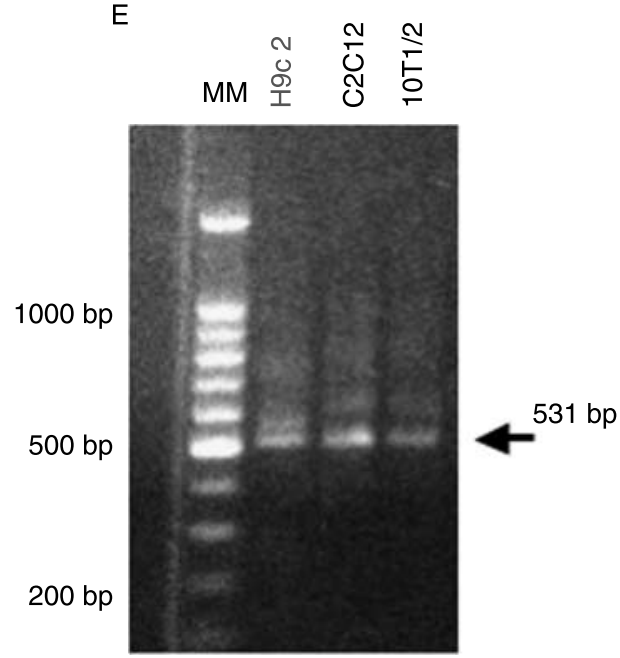

Myostatin

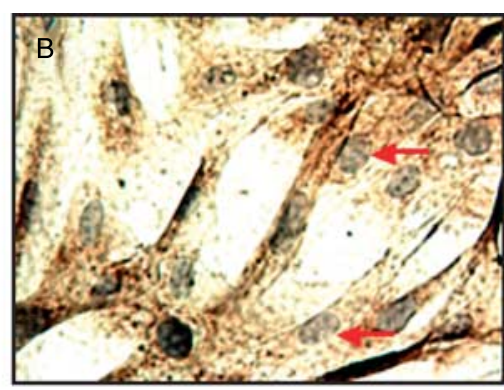

Cardiac Troponin I

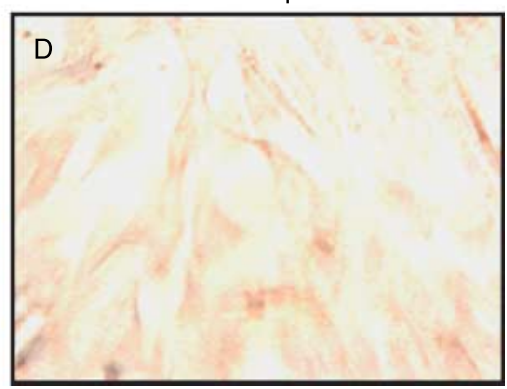

MHC type II

F

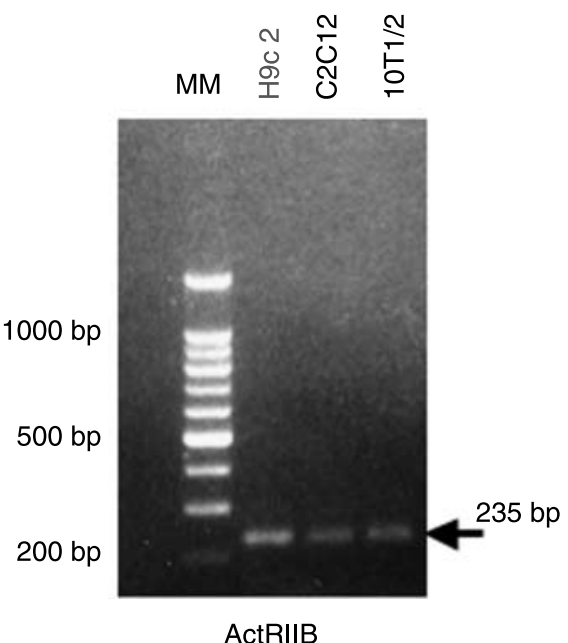

Figure 5 Cultures of H9c2 embryonic cardiomyocytes express both myostatin and its receptor.

(A-D) H9c2 cells were plated onto 8-well removable chamber plates and subjected to immunocytochemistry as indicated. (E and F) Total RNA was isolated from H9c2 cells and subjected to RT-PCR with primers as indicated. RNA from $\mathrm{C}_{2} \mathrm{C}_{12}$ and $\mathrm{C} 3 \mathrm{H} 10 \mathrm{~T}(1 / 2)$ cells was used as reference.

image the hearts of both mice and rats, and in our opinion the visualization of the ventricular cavity is superior to that obtained by echocardiography. Since fluoroscopy was performed at the same time following anesthesia in all animals, the slowing effects of ketamine/xylazine on the heart affected them similarly. While no formal specific sensitivity/reproducibility studies have been performed with this procedure, the data generated by this technique has yielded consistent data when studying rat myocardial infarcts (Muller-Ehmsen et al. 2002, Yao et al. 2003, Dai et al. 2005). This same technique has been used to analyze in vivo ventricular function of the normal and pressure overloaded right ventricle (Rockman et al. 1994).

We do not know whether inhibition of Mst by administration of Mst antagonists in humans would cause myocardial 
A

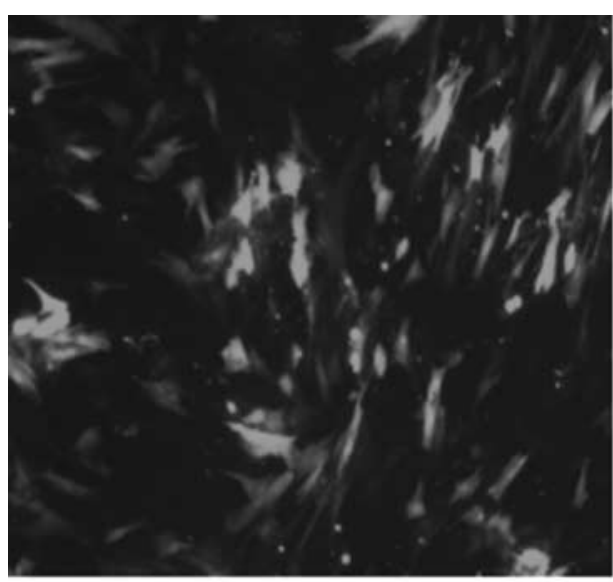

pCMV/EGFP:pCMV/Mst

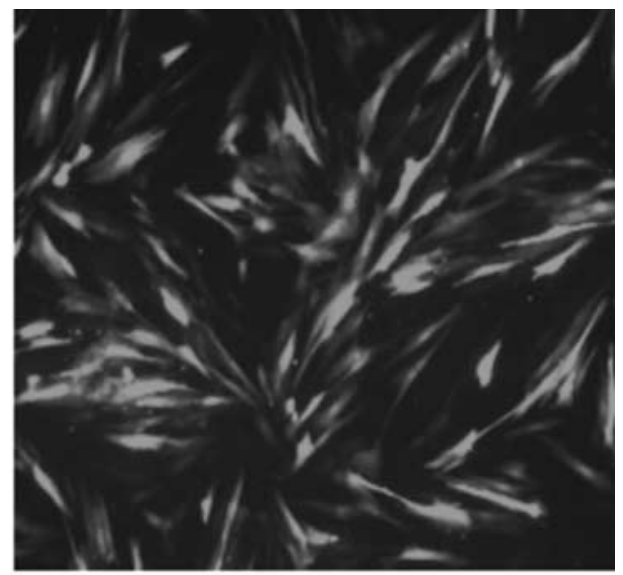

pMCK/EGFP:pMCK/Mst

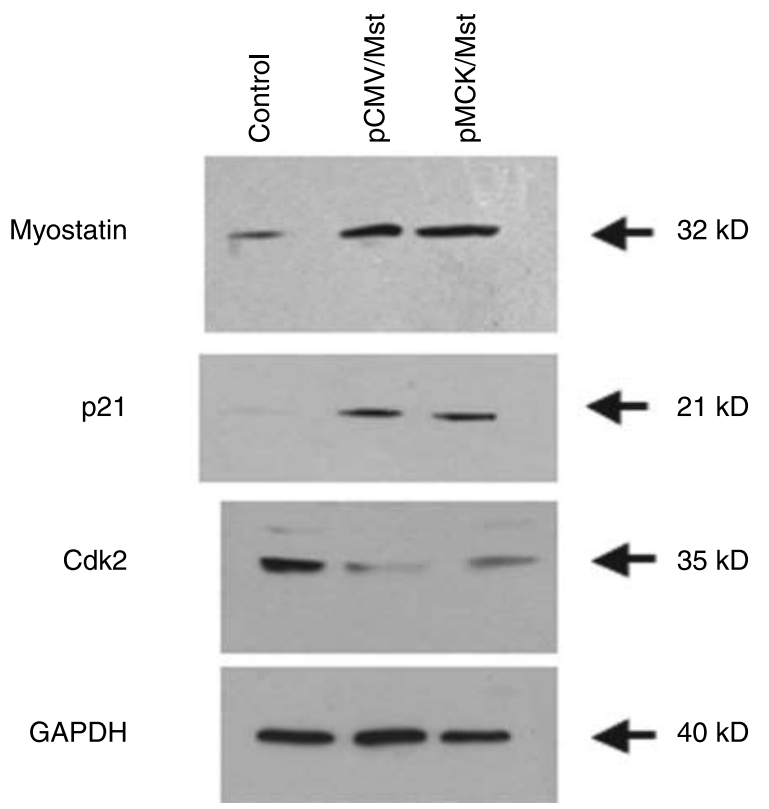

Figure 6 Expression of recombinant myostatin by cultured cardiomyocytes affects the expression of cell cycle proteins. (A) H9c2 cardiomyocytes were transfected with plasmid vectors driven by the CMV or MCK promoters that express EGFP as reporter protein, and examined at 2 days under the fluorescent inverted microscope. (B) H9c2 cells were transfected with constructs encoding the myostatin full length coding region in the same vectors as in A, or left untreated (control), and cell homogenates were subjected to western blot analysis for the indicated protein, using GAPDH in each case as housekeeping protein.

hypertrophy, and whether this hypertrophic response is beneficial or deleterious. No morphometric histological analysis of the heart was performed in the current study. However, a very recent paper has addressed this issue in the Mst knockout mouse (Cohn et al. 2007), showing that no cardiomyocyte hypertrophy was evident in aged (2 years old) Mst $(-/-)$ mouse versus the WT animal with Bl/6 background. Interestingly, the measurements performed by echocardiography measurements under ketamine/xylazine coincide with our corresponding results with the XiScan small imaging amplifier, where no significant differences are apparent between Mst $(-/-)$ and WT in both $\mathrm{Bl} / 6$ and Balb c backgrounds.

The maintenance of a constant functional efficacy per unit of cardiac or skeletal muscle mass irrespective on how the latter is affected by variations in Mst levels, is counterintuitive to the putative effects of Mst on tissue composition, derived from its effect in vitro where this protein not only inhibits myogenic differentiation from pluripotent cells (Artaza et al. 
A

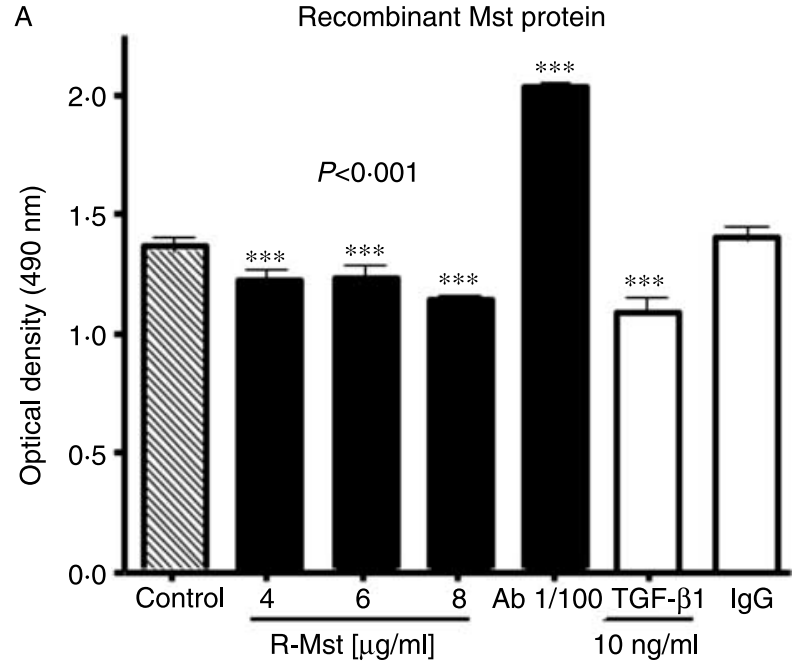

B

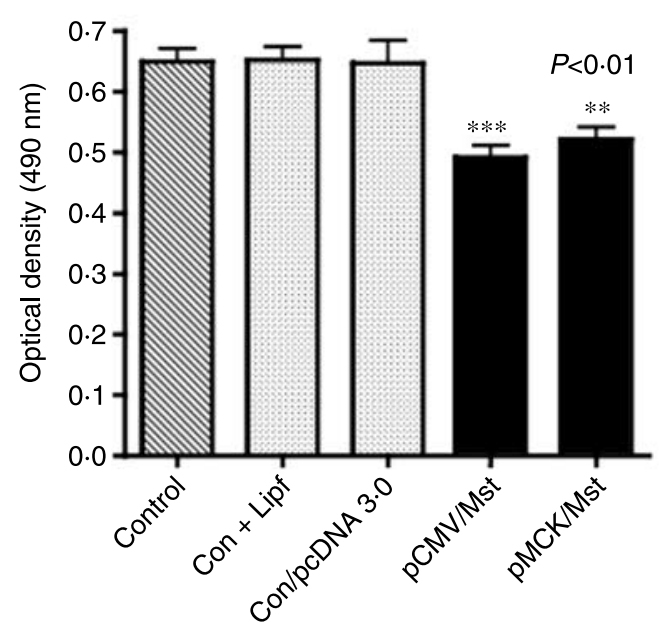

Figure 7 Cardiomyocyte cell proliferation is reduced by expression of either exogenous or endogenous recombinant myostatin protein, and increased by the inhibition of myostatin activity. (A) H9c2 cells were incubated for 4 days, as follows: control: no addition, R-Mst: increasing concentrations of recombinant myostatin protein corresponding to the 110 aa (carboxy terminus); $\mathrm{Ab}$ 1/100: polyclonal IgG antibody against myostatin, diluted to $0 \cdot 1 \mu \mathrm{g} / \mathrm{ml}$; TGF $\beta 1$ : used as reference protein; IgG: control non-immune IgG diluted to $0 \cdot 1 \mu \mathrm{g} / \mathrm{ml}$. (B) H9c2 cells were transfected and maintained for 4 days, as follows: control: no transfection; Con \pm Lipf: transfection with lipofectamine only; Con/pcDNA3.0: transfection with empty CMV-driven vector; $\mathrm{pCMV/Mst:} \mathrm{transfection}$ with CMV driven construct of full length myostatin cDNA; pMCK/Mst: transfection with equivalent myostatin construct, but driven by the MCK promoter.

2005), but also promotes their adipogenic and fibrogenic conversion (Artaza et al. 2006, Tsao et al. 2006). Moreover, in vivo Mst expression is associated with skeletal muscle fibrosis both in normal and dystrophic mice (Wagner et al. 2002, McCroskery et al. 2005, Parsons et al. 2006). Therefore, we hypothesized that connective tissue and fat infiltration would occur in the Mst TG heart in parallel to the reduction in organ size, and this would impair the fractional ejection volume. The absence of this functional alteration implies that during embryo development and early postnatal life, the factors that may act in conjunction with Mst to trigger lipofibrotic degeneration of the heart, such as TGF $\beta 1$ (Khan \& Sheppard 2006) are absent or non-operative, or there is an intense level of cardiac repair maintaining the normal tissue composition.

Since our animals were only 7 weeks old, it may be worth to determine in future studies whether in aged animals, where cardiac fibrosis and dysfunction occur (Hacker et al. 2006, Rozenberg et al. 2006), the pro-lipofibrotic effects of Mst prevail and this translates into a further aggravation of these processes. In fact, although lipid composition was not analyzed, at 2 years of age, the heart of the Mst null mice displays normal histological features as assessed with Masson trichrome (Cohn et al. 2007). However, the converse situation that fibrosis may occur more intensively in mice overexpressing was not studied. Therefore, the possibility of Mst inducing fibrosis in the heart in certain conditions remains open, despite the findings of the authors that the absence of Mst did not prevent cardiac fibrosis in the Mst $-/-/ \mathrm{mdx}$ hybrid mouse.

Our data demonstrate that Mst inhibits proliferation of H9c2 cardiomyocytes. Western blot analysis confirmed that incubation of $\mathrm{H} 9 \mathrm{c} 2$ cardiomyocytes with recombinant Mst protein upregulated $\mathrm{p} 21$, an inhibitor of cdk; additionally, $\mathrm{cdk} 2$ expression was downregulated. These findings were confirmed in separate experiments in which H9c2 cardiomyocytes were transfected with a Mst cDNA expression constructs which revealed that Mst inhibits G1 to S phase progression. These data on Mst effects on cardiomyocytes are analogous to those reported in cultures of skeletal myoblasts in which Mst also has been shown to inhibit cell replication, mainly by interfering with the progression into $S$ phase of the cell cycle (Artaza et al. 2002, McCroskery et al. 2003, Sakuma et al. 2004, Shyu et al. 2005, McFarland et al. 2006, Tsao et al. 2006). Our results with the H9c2 cell line also coincide with a very recent study (McKoy et al. 2007) in primary rat embryonic cardiomyocytes showing that Mst is expressed faintly in these cells, and that recombinant Mst inhibits cell proliferation via upregulation of p21 and Smad2 phosphorylation, thus blocking the $\mathrm{G} 1$ to $\mathrm{S}$ phase progression.

Our finding that Mst is expressed, albeit at very low levels, in the heart of 7-week old WT mice, and that both Mst mRNA and protein and Mst receptor, the ActRIIB, are all detected in the H9c2 rat cardiomyocyte cell line, raises several questions. The precise functional role of endogenous Mst in the postnatal heart or of the circulating Mst secreted by the skeletal muscle (Gonzalez-Cadavid et al. 1998, Hill et al. 2002, 2003, Rios et al. 2004) that may reach the heart is unknown. It is possible that upregulation of endogenous Mst production may be involved in cardiac remodeling and scarring after myocardial infarction, as has been shown previously in sheep 
A

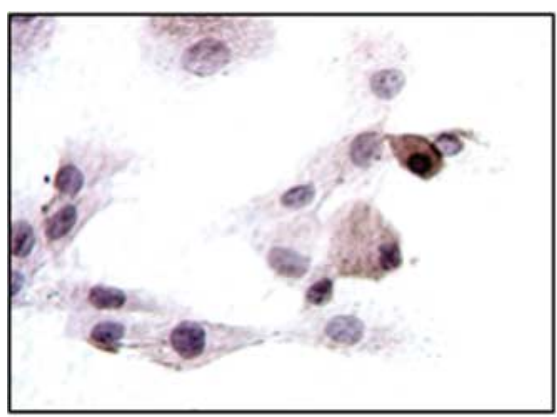

Control

B
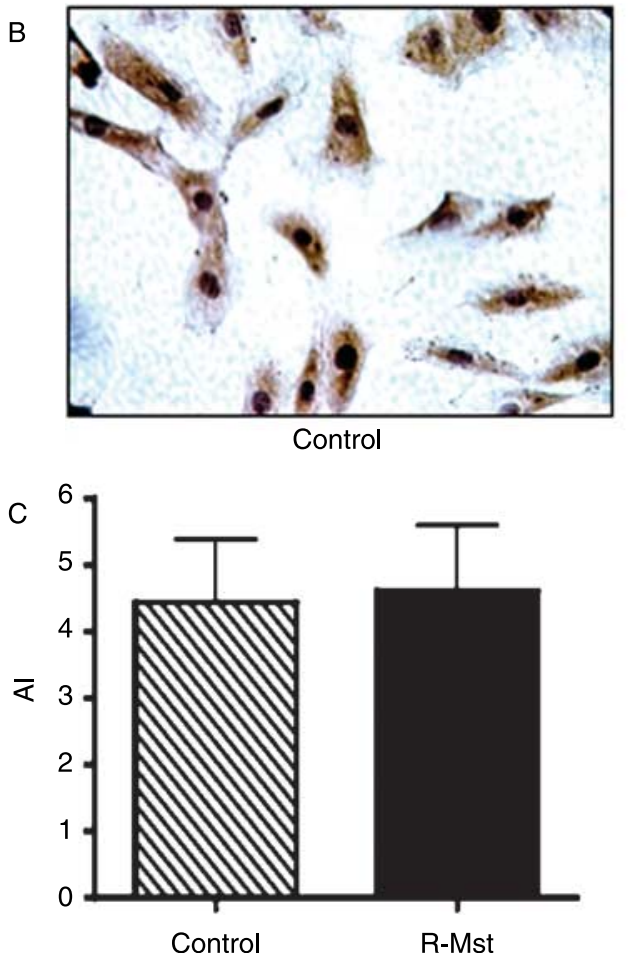

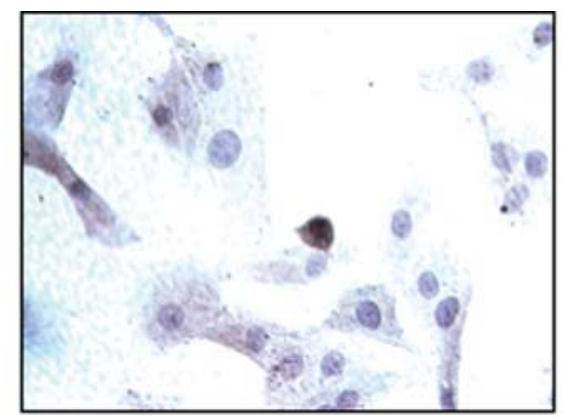

R-Mst $(\mu \mathrm{g} / \mathrm{ml})$

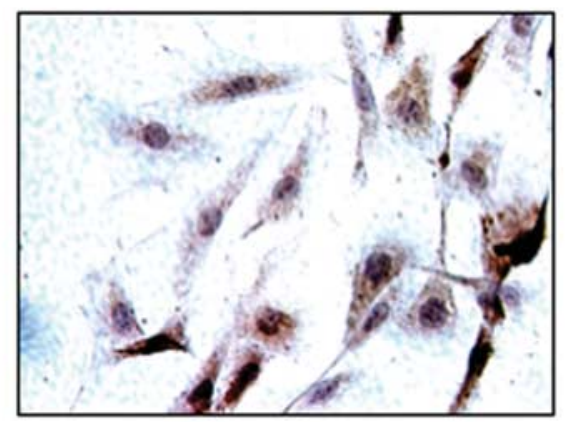

R-Mst $(\mu \mathrm{g} / \mathrm{ml})$

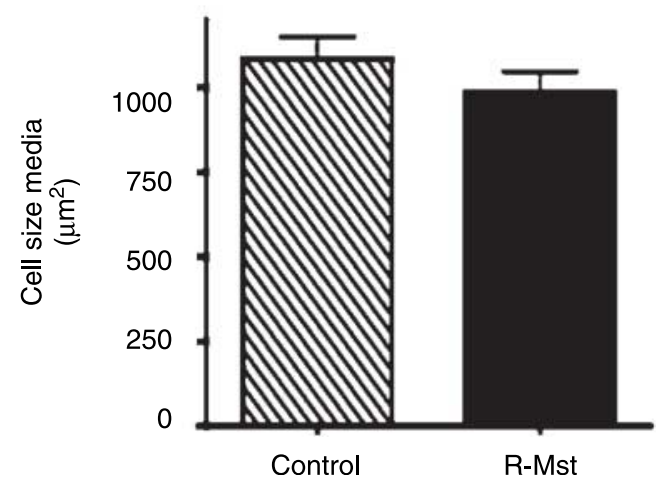

Figure 8 Myostatin does not affect cardiomyocyte apoptotic index or size. H9c2 cells were incubated for 4 days, as follows: control: no addition, R-Mst: $4 \mu \mathrm{g} / \mathrm{ml}$ of recombinant myostatin protein corresponding to the 110 aa (carboxy terminus), as in Fig. 7. (A) Representative fields of cells stained by TUNEL. (B)

Representative fields of cells stained for cardiac troponin I. (C) Quantitative image analysis of TUNEL stained sections (left) or of cell size (right).

(Sharma et al. 1999). In this respect, our Mst TG mouse, by moderately overexpressing Mst in the heart, may replicate this condition, not only in animals but also speculatively in humans too. Others have speculated that Mst may act as a chalone to regulate myocardial growth in response to hypertrophic or atrophic signals. Thus, Mst has been reported to be upregulated in states of cardiac hypertrophy induced by phenylephrine infusion and Akt hyperexpression (Gaussin \& Depre 2005). This hypothesis merits further investigation.

The inhibition of cardiomyocyte proliferation by Mst observed in vitro may be responsible for the reduction in heart growth in the Mst transgenic mice that overexpress Mst. It is noteworthy that we did not observe any change of cell size or multinucleation by Mst in vitro, upon reducing cell replication despite the fact that $\mathrm{H} 9 \mathrm{c} 2$ can undergo hypertrophy under different stimuli, for instance oxidative stress caused by $\mathrm{H}_{2} \mathrm{O}_{2}$ (Chen et al. 2000), doxorubicin (Merten et al. 2006), TGF $\beta$ (Huang et al. 2004), or vasopressin (Brostrom et al. 2001). Our observations that Mst did not affect apoptosis in $\mathrm{H} 9 \mathrm{c} 2$ cultures are compatible with what we reported in skeletal myoblast cultures (Taylor et al. 2001). H9c2 cells do respond to cardiacrelevant apoptotic stimuli, such as hypoxia combined with serum deprivation (Tantini et al. 2006). In addition, it is notable that in Mst transgenic mice in which Mst expression was driven by MCK-3E reporter, which restricted the Mst transgene expression to the skeletal muscle, the cardiac mass 
did not differ from that in WT controls. Taken together, these data suggest a paracrine or autocrine effect of Mst on the heart during gestational development or early postnatal growth rather than an endocrine effect.

In summary, we have shown that Mst overexpression in transgenic mice is associated with decreased cardiac and left ventricular mass but normal left ventricular EF. Mst inhibits cardiomyocyte proliferation by inhibiting progression through the $\mathrm{S}$ phase of the cell cycle, without affecting apoptosis or cell size. Long-term effects of Mst inhibition in adult and aged mammals on left ventricular mass and function need further investigation as they are relevant to the clinical application of Mst antagonists as anabolic therapies in humans.

\section{Funding}

This work was supported by NIH grants: MBRS Score Program 3S06GM068510-02S21 (J N A), RCMIG12RR003026, 2U01 AG014369 (S B), and Drew-UCLA Reproductive Science Research Center Grant U54HD041748-01. Grant Number 1 P20 MD000545 from the National Center on Minority Health and Health Disparities, NIH also supports JNA and SRP. The authors declare that there is no conflict of interest that would prejudice the impartiality of this scientific work.

\section{References}

Artaza J, Bhasin S, Mallidis C, Taylor W, Ma K \& Gonzalez-Cadavid NF 2002 Endogenous expression and localization of myostatin and its relation to myosin heavy chain distribution in C2C12 skeletal muscle cells. Journal of Cellular Physiology 190 170-179.

Artaza JN, Bhasin S, Magee TR, Reisz-Porszasz S, Shen R, Groome NP, Meerasahib MF \& Gonzalez-Cadavid NF 2005 Myostatin inhibits myogenesis and promotes adipogenesis in C3H $10 \mathrm{~T}(1 / 2)$ mesenchymal multipotent cells. Endocrinology 146 3547-3557.

Artaza JN, Singh R, Ferrini MG, Braga M, Gonzalez-Cadavid NF 2006 Myostatin promotes collagen deposition in C3H $10 \mathrm{~T}(1 / 2)$ mesenchymal multipotent cells through the SMAD signaling pathway. Endocrine Society Meeting, Boston, MA, P1-430. (Abstract).

Brostrom MA, Mourad F \& Brostrom CO 2001 Regulated expression of GRP78 during vasopressin-induced hypertrophy of heart-derived myocytes. Journal of Cellular Biochemistry 83 204-217.

Bunger L, Ott G, Varga L, Schlote W, Rehfeldt C, Renne U, Williams JL \& Hill WG 2004 Marker-assisted introgression of the compact mutant myostatin allele MstnCmpt-dl1 Abc into a mouse line with extreme growth effects on body composition and muscularity. Genetical Research $\mathbf{8 4}$ 161-173.

Caiozzo V, Reisz-Porszasz S, Bhasin S, Gonzalez-Cadavid N 2005 Mechanical properties of plantaris muscle in myostatin knock out mice. FASEB/ Experimental Biology Meeting, San Diego, LB 136. (Abstract).

Chen QM, Tu VC, Wu Y \& Bahl JJ 2000 Hydrogen peroxide dose dependent induction of cell death or hypertrophy in cardiomyocytes. Archives of Biochemistry and Biophysics 373 242-248.

Cohn RD, Liang HY, Shetty R, Abraham T \& Wagner KR 2007 Myostatin does not regulate cardiac hypertrophy or fibrosis. Neuromuscular Disorders 17 290-296.
Cook SA, Matsui T, Li L \& Rosenzweig A 2002 Transcriptional effects of chronic Akt activation in the heart. Journal of Biological Chemistry 277 22528-22533

Dai W, Hale SL, Martin BJ, Kuang JQ, Dow JS, Wold LE \& Kloner RA 2005 Allogeneic mesenchymal stem cell transplantation in postinfarcted rat myocardium: short- and long-term effects. Circulation 112 214-223.

Dominique JE \& Gerard C 2006 Myostatin regulation of muscle development: molecular basis, natural mutations, physiopathological aspects. Experimental Cell Research 312 2401-2414.

Ferrini MG, Magee TR, Vernet D, Qian A, Valente EG, Bhasin S, Rajfer J \& Gonzalez-Cadavid NF 2004 Myostatin is expressed in the normal tunica albuginea and Peyronie's fibrotic plaque in parallel to myofibroblast differentiation. Journal of Urology 171329 (A1248).

Gaussin V \& Depre C 2005 Myostatin, the cardiac chalone of insulin-like growth factor-1. Cardiovascular Research 68 347-349.

Gonzalez-Cadavid NF, Taylor WE, Yarasheski K, Sinha-Hikim I, Ma K, Ezzat S, Shen R, Lalani R, Asa S, Mamita M et al. 1998 Organization of the human myostatin gene and expression in healthy men and HIV-infected men with muscle wasting. PNAS 95 14938-14943

Gregory DJ, Waldbieser GC \& Bosworth BG 2004 Cloning and characterization of myogenic regulatory genes in three Ictalurid species. Animal Genetics 35 425-430.

Hacker TA, McKiernan SH, Douglas PS, Wanagat J \& Aiken JM 2006 Agerelated changes in cardiac structure and function in Fischer $344 \times$ Brown Norway hybrid rats. American Journal of Physiology. Heart and Circulatory Physiology 290 H304-H311.

Hill JJ, Davies MV, Pearson AA, Wang JH, Hewick RM, Wolfman NM \& Qiu Y 2002 The myostatin propeptide and the follistatin-related gene are inhibitory binding proteins of myostatin in normal serum. Journal of Biological Chemistry 277 40735-40741.

Hill JJ, Qiu Y, Hewick RM \& Wolfman NM 2003 Regulation of myostatin in vivo by growth and differentiation factor-associated serum protein-1: a novel protein with protease inhibitor and follistatin domains. Molecular Endocrinology 17 1144-1154.

Huang CY, Kuo WW, Chueh PJ, Tseng CT, Chou MY \& Yang JJ 2004 Transforming growth factor-beta induces the expression of ANF and hypertrophic growth in cultured cardiomyoblast cells through ZAK. Biochemical and Biophysical Research Communications 324 424-431.

Khan R \& Sheppard R 2006 Fibrosis in heart disease: understanding the role of transforming growth factor-beta in cardiomyopathy, valvular disease and arrhythmia. Immunology 118 10-24.

Lee S-J 2004 Regulation of muscle mass by myostatin. Annual Review of Cell and Developmental Biology 20 61-86.

Magee TR, Artaza JN, Ferrini MG, Zuniga FI, Cantini L, Reisz-Porszasz S, Rajfer J \& Gonzalez-Cadavid NF 2006 Myostatin $\operatorname{sh}$ NA gene therapy increases muscle mass. Journal of Gene Medicine 8 1171-1181.

McCroskery S, Thomas M, Maxwell L, Sharma M \& Kambadur R 2003 Myostatin negatively regulates satellite cell activation and self-renewal. Journal of Cell Biology 162 1135-1147.

McCroskery S, Thomas M, Platt L, Hennebry A, Nishimura T, McLeay L, Sharma M \& Kambadur R 2005 Improved muscle healing through enhanced regeneration and reduced fibrosis in myostatin-null mice. Journal of Cell Science 118 3531-3541.

McFarland DC, Velleman SG, Pesall JE \& Liu C 2006 Effect of myostatin on turkey myogenic satellite cells and embryonic myoblasts. Comparative Biochemistry and Physiology. Part A, Molecular and Integrative Physiology 144 501-508.

McKoy G, Bicknell KA, Patel K \& Brooks G 2007 Developmental expression of myostatin in cardiomyocytes and its effect on foetal and neonatal rat cardiomyocyte proliferation. Cardiovascular Research 74 304-312.

McPherron AC \& Lee SJ 1997 Double muscling in cattle due to mutations in the myostatin gene. PNAS 94 12457-12461.

McPherron AC, Lawler AM \& Lee SJ 1997 Regulation of skeletal muscle mass in mice by a new TGF-beta superfamily member. Nature $38783-90$.

Merten KE, Jiang Y, Feng W \& Kang YJ 2006 Calcineurin activation is not necessary for Doxorubicin-induced hypertrophy in $\mathrm{H} 9 \mathrm{c} 2$ embryonic rat cardiac cells: involvement of the phosphoinositide 3-kinase-Akt pathway. Journal of Pharmacology and Experimental Therapeutics 319 934-940. 
Morissette MR, Cook SA, Foo S, McKoy G, Ashida N, Novikov M, Scherrer-Crosbie M, Li L, Matsui T, Brooks G et al. 2006 Myostatin regulates cardiomyocyte growth through modulation of Akt signaling. Circulation Research 99 15-24.

Muller-Ehmsen J, Peterson KL, Kedes L, Whittaker P, Dow JS, Long TI, Laird PW \& Kloner RA 2002 Rebuilding a damaged heart: long-term survival of transplanted neonatal rat cardiomyocytes after myocardial infarction and effect on cardiac function. Circulation 105 1720-1726.

Ostbye TK, Galloway TF, Nielsen C, Gabestad I, Bardal T \& Andersen O 2001 The two myostatin genes of Atlantic salmon (Salmo salar) are expressed in a variety of tissues. European Journal of Biochemistry 268 5249-5257.

Parsons SA, Millay DP, Sargent MA, McNally EM \& Molkentin JD 2006 Age dependent effect of myostatin blockade on disease severity in a murine model of limb-girdle muscular dystrophy. American Journal of Pathology 168 1975-1985.

Reisz-Porszasz S, Bhasin S, Artaza JN, Shen R, Sinha-Hikim I, Hogue A, Fielder TJ \& Gonzalez-Cadavid NF 2003 Lower skeletal muscle mass in male transgenic mice with muscle-specific overexpression of myostatin. American Journal of Physiology. Endocrinology and Metabolism 285 E876-E888.

Rios R, Fernandez-Nocelos S, Carneiro I, Arce VM \& Devesa J 2004 Differential response to exogenous and endogenous myostatin in myoblasts suggests that myostatin acts as an autocrine factor in vivo. Endocrinology 145 2795-2803.

Rockman HA, Ono S, Ross RS, Jones LR, Karimi M, Bhargava V, Ross J Jr \& Chien KR 1994 Molecular and physiological alterations in murine ventricular dysfunction. PNAS 91 2694-2698.

Rozenberg S, Tavernier B, Riou B, Swynghedauw B, Page CL, Boucher F, Leiris J \& Besse S 2006 Severe impairment of ventricular compliance accounts for advanced age-associated hemodynamic dysfunction in rats. Experimental Gerontology 41 289-295.

Sakuma K, Nakao R, Inashima S, Hirata M, Kubo T \& Yasuhara M 2004 Marked reduction of focal adhesion kinase, serum response factor and myocyte enhancer factor $2 \mathrm{C}$, but increase in RhoA and myostatin in the hindlimb dy mouse muscles. Acta Neuropathologica 108 241-249.

Schreier T, Kedes L \& Gahlmann R 1990 Cloning, structural analysis, and expression of the human slow twitch skeletal muscle/cardiac troponin C gene. Journal of Biological Chemistry 265 21247-21253.

Schuelke M, Wagner KR, Stolz LE, Hubner C, Riebel T, Komen W, Braun T, Tobin JF \& Lee SJ 2004 Myostatin mutation associated with gross muscle hypertrophy in a child. New England Journal of Medicine 350 2682-2688.

Sharma M, Kambadur R, Matthews KG, Somers WG, Devlin GP, Conaglen JV, Fowke PJ \& Bass JJ 1999 Myostatin, a transforming growth factor-beta superfamily member, is expressed in heart muscle and is upregulated in cardiomyocytes after infarct. Journal of Cellular Physiology 180 1-9.

Shield MA, Haugen HS, Vlegg CH \& Hauschka SD 1996 E-box sites and a proximal regulatory region of the muscle creatine kinase gene differentially regulate expression in diverse skeletal muscle and cardiac muscle of transgenic mice. Molecular and Cellular Biology 16 5058-5068.
Shyu KG, Ko WH, Yang WS, Wang BW \& Kuan P 2005 Insulin-like growth factor-1 mediates stretch-induced upregulation of myostatin expression in neonatal rat cardiomyocytes. Cardiovascular Research 68 405-414.

Shyu KG, Lu MJ, Wang BW, Sun HY \& Chang H 2006 Myostatin expression in ventricular myocardium in a rat model of volume-overload heart failure. European Journal of Clinical Investigation 36 713-719.

Szabo G, Dallmann G, Muller G, Patthy L, Soller M \& Varga L 1998 A deletion in the myostatin gene causes the compact $(\mathrm{Cmpt})$ hypermuscular mutation in mice. Mammalian Genome 9 671-672.

Tantini B, Fiumana E, Cetrullo S, Pignatti C, Bonavita F, Shantz LM Giordano E, Muscari C, Flamigni F, Guarnieri C et al. 2006 Involvement of polyamines in apoptosis of cardiac myoblasts in a model of simulated ischemia. Journal of Molecular and Cellular Cardiology 40 775-782.

Taylor W, Bhasin S, Artaza J, Byhower F, Azam MA, Willard DH, Kull F \& Gonzalez-Cadavid NF 2001 Myostatin inhibits cell proliferation and protein synthesis in C2C12 muscle cells. American Journal of Physiology 280 E221-E228.

Tsao J, Vernet D, Nolazco G, Artaza JN \& Gonzalez-Cadavid NF 2006 Androgen modulation of cell lineage commitment by muscle-derived stem cells. Journal of Investigative Medicine 54 S97 (Abstract).

Tsuchida K 2006 The role of myostatin and bone morphogenetic proteins in muscular disorders. Expert Opinion on Biological Therapy 6 147-154.

Wagner KR, McPherron AC, Winik N \& Lee SJ 2002 Loss of myostatin attenuates severity of muscular dystrophy in mdx mice. Annals of Neurology 52 832-836.

Yao M, Dieterle T, Hale SL, Dow JS, Kedes LH, Peterson KL \& Kloner RA 2003 Long-term outcome of fetal cell transplantation on postinfarction ventricular remodeling and function. Journal of Molecular and Cellular Cardiology 35 661-670.

Yarasheski KE, Bhasin S, Sinha-Hikim I, Pak-Loduca J \& Gonzalez-Cadavid NF 2002 Serum myostatin-immunoreactive protein is increased in 60-92 year old women and men with muscle wasting. Journal of Nutrition, Health and Aging 6 343-348.

Zhu X, Hadhazy M, Wehling M, Tidball JG \& McNally EM 2000 Dominant negative myostatin produces hypertrophy without hyperplasia in muscle. FEBS Letters 474 71-75.

Zimmers TA, Davies MV, Koniaris LG, Haynes P, Esquela AF, Tomkinson KN, McPherron AC, Wolfman NM \& Lee SJ 2002 Induction of cachexia in mice by systemically administered myostatin. Science 296 1486-1488.

Received in final form 25 March 2007

Accepted 1 April 2007

Made available online as an Accepted Preprint 11 April 2007 